ining the distribution of hydrogen in the galaxy. The significance of the observations and the deductions which may be drawn from them are briefly discussed; and the report concludes with a list of the scientific institutions engaged in research on the 21-cm. line.

All three reports contain a comprehensive, but selected, list of references to the specific portions of the field of radio astronomy to which they refer. The fact that they were prepared by small groups of international workers makes them invaluable to all who are studying or pursuing research in this subject.

R. L. Smith-Rose

\section{BIOLOGY AND HUMAN AFFAIRS}

CHANGES in educational thought and practice 1 are usually so slight that they are scarcely discernible from one year to another; as time goes on they may build up into something formidable. Twenty years ago, for example, the teaching of biology in British schools was on a small scale. In many girls' schools botany was thought to be the only suitable biological subject, while in boys' schools botany was thought to be a subject suitable for girls, and little, except a smattering of 'nature study', was taught.

In 1935 the British Social Hygiene Council (now the British Social Biology Council), a voluntary organization formed originally to combat the venereal diseases, took the long view and turned to the educational service as a means of giving children rational information about the workings of their own bodies. It was expecting that actions based on this knowledge would lead to higher standards of health, and was hoping that a deeper insight into biology would endow men and women with a clearer appreciation of themselves as human beings; when associated with the understanding provided by the other life sciences, this would form the basis for better moral behaviour, particularly in relation to sex. The Council decided that its long-term objectives would best be achieved by promoting and supporting the development of biology teaching in schools. Public meetings were organized, as well as conferences, courses for teachers and summer schools. A journal, then called Biology, was launched, and now, under the name of Biology and Human Affairs, is celebrating twenty years of uninterrupted pub. lication.

During those twenty years changes in three different directions have been accompanied by corresponding changes in the nature of the journal itself. First, there has been a remarkable increase in the amount of biology teaching in schools. To-day the subject is taught in many grammar schools, and it is becoming firmly established in secondary modern and primary schools, although in some of these there is a tendency to offer it only to boys, while girls are busy with domestic science. Secondly, there has been a marked improvement in the content of the subjectmatter. It is developing into a genuine natural science, having depth as well as breadth; botany has been largely displaced by biology, a unified subject drawing its material and principles from both plants and animals.

The third direction in which progress has been marked is in the field of sex education. From its inception in 1914 until it ceased to be a semi-official body in 1942, the British Social Hygiene Council's main function was to act as a central organization for public enlightenment in relation to venereal disease. It was with this object in mind that the Council embarked on a vigorous campaign in favour of sex-education. At first it met with bitter opposition, particularly from religious bodies and official organizations, and sometimes from the schools, while those most favourably disposed towards this new development but who were least able to make their views effective were the children themselves. Bit by bit, however, the opposition was won over, and when in 1943 the Ministry of Education issued its pamphlet on "Sex-Education in Schools and Youth Organizations" the campaign might be said to have achieved its object. It would, of course, be presumptuous for the founders of Biology to claim credit for all these advances; they deserve their proportionate share.

To-day, Biology and Human Affairs appears as the journal of an organization, the British Social Biology Council, which is committed to promote and encourage the teaching of human biology as a cultural and practical subject; to preserve and strengthen the family as the basic social unit; and to encourage the dissemination of biological knowledge as a means of emphasizing the social responsibilities of individuals, the implications of population problems, the removal of conditions conducing to promiscuity, the elimination of commercialized vice, and a reduction in the incidence of social diseases, particularly the venereal diseases. The contents of its anniversary number indicate the broad catholic way in which those responsible for the production of the journal are seeking to implement the aims of its parent body. Articles include one on the adaptation of farm animals to their environment, by Dr. John Hammond; the fauna of built-up areas, by Dr. E. J. Popham; the natural history of the 'spiv', by Dr. P. D. Scott; the breeding behaviour of toads; a progress report on poliomyelitis; and the adventures and vicissitudes of a laboratory technician, by F. C. Taylor, senior laboratory steward at Eton College.

\section{HOSPITAL IN-PATIENT STATISTICS IN ENGLAND AND WALES}

A $S$ part of the Registrar General's statistical review of England and Wales for the two years 1950-51, a "Supplement on Hospital In-Patient Statistics" has been published* which makes available a fresh selection of material from a hospital in-patient inquiry started in 1949. The chief purposes of the inquiry were to assist hospital administrators by a more detailed analysis of the diseases treated and the types of patients involved; and also to increase the information available about the general pattern of ill-health in the community obtainable from mortality and morbidity data. Since the inquiry has, up to the present, been largely experimental, it has covered only a proportion of hospitals; and, moreover, different selections of tables arc presented for the several years analysed. Sufficient experience has now been gained to put the project on a more permanent and comprehensive basis.

* The Registrar General's Statistical Review of England and Wales for the two years 1950-51: Supplement on Hospital In-Patient Statistics. Pp. iv +151 . (London: H.M.S.O., 1955.) 78. 6d. net. 
Attention is focused in this supplement on the patients' length of stay in hospital, and a variety of different types of analysis have been made involving various cross-classifications by hospital group, diagnosis, sex, age and social class. Admissions for childbirth and diseases of pregnancy have been excluded from the main tables; but a separate analysis of length of stay according to birth-weight is provided. There is also one appendix listing the participating hospitals with an age-and-sex distribution of discharges, and another giving the same type of distribution for patients actually in National Health Service hospitals on the night of the 1951 Census.

It is particularly gratifying to a statistician to see emphasis being laid on statistical frequency distributions as opposed to mere averages. Theoretical studies of fluctuations in waiting-lists, for example, are dependent on knowing the actual form of the distribution of length of stay. Again, variations in the latter with district, social class, the elapse of time, otc., are also of clinical importance. One curious point in connexion with the grouping of the frequency distributions is perhaps worth directing attention to. In Table 2, for example, the grouping is by single days up to 20 , and then in tens up to 100 , with coarser grouping in the tail. This seems quite reasonable and enables one to $s e \theta$ the general shape of the curve at a glance. Tables 5 and 6 , on the other hand, employ two different arrangements, each involving a mixture of intervals grouped in $1,2,3,4,7,21$, etc., days. Although one cannot say that this is wrong, a more uniform presentation would certainly make the tables easier to use and interpret.

It is, of course, most valuable to have this material on the distribution of length of stay, especially as it may be more comprehensive in future. At the same time, it must be pointed out that much more than this is required by administrators using hospital statisties to gauge the efficiency with which the demand for in-patient care is being met. Valid conclusions have to be based on considering several inter-related items, including bed allocation, bed occupancy, turnover interval, discharges and deaths (or admissions), and waiting lists as well as length of stay.

NORMAN T. J. BAILEY

\section{ROCKEFELLER FOUNDATION AWARDS}

A

MONG the grants recently made by the Rockefeller Foundation, New York, are the following :

\section{Royal Institution, London, and Cavendish Laboratory, Cambridge}

An award of 30,300 dollars has been made to the Davy Faraday Laboratory of the Royal Institution and one of 40,000 dollars to the University of Cambridge for the Medical Research Council's Unit in the Cavendish Laboratory, to aid the researches on proteins at these centres.

It is now more than twenty years since Prof. J. D. Bernal and Dr. D. Crowfoot announced in Nature that they had obtained X-ray diffraction photographs of a protein crystal. To interpret these photographs and get information about the structure of molecules which contain thousands of atoms has for long seemed a task of such complexity that one could scarcely hope for success. Quite recently, however, the most formidable obstacle has been overcome. M. F. Perutz has shown that heavy atoms or groups can be attached at definite places in the hæmoglobin molecule without disturbing the crystal. line structure, and that by measuring the consequent changes in the intensity of diffraction, the phases of the reflexions can be determined and the structure computed. This opens up a vast new field for crystal analysis which is now being explored at a number of laboratories. New ways of attaching heavy groups to various parts in the molecule are being discovered, and these groups can be located. A beginning can be made in the task of mapping out the positions in the molecule of certain amino-acid residues or other groups, and eventually of linking them up by the intervening structure.

The Unit at Cambridge, under Dr. M. Perutz and Dr. J. C. Kendrew, and the group at the Davy Faraday Laboratory under my direction are working in complete collaboration on these problems, studying in particular the structures of hæmoglobin and myoglobin. Quite apart from the new insight which will certainly be gained into the part which these molecules play in living matter, the solution of the technical problem of applying X-ray analysis to such vast molecules is very thrilling indeed.

LAWRENCE BragG

\section{Chemical Crystallography Laboratory, Oxford}

Over the past twenty years I have been interested. in the possibility of using $\mathbf{X}$-ray crystallographic methods to find the arrangement of the atoms in protein molecules and particularly in insulin. One of many possible approaches to solving this problem seems to be the erystallographic study of naturally occurring peptides such as the gramicidins and tyrocidine or oxytocin and vasopressin. These all have molecules much smaller in size than even the smallest protein molecules; some indeed are smaller than vitamin $B_{12}$, of which we have already found it possible to obtain the kind of information we require.

Dr. R. L. M. Synge has accordingly prepared for us a series of heavy-atom derivatives of gramicidin $S$ and we are now making some progress with the detailed X-ray analysis of one group of these. We already have evidence that there may be a connexion between the way the peptide chain is folded in gramicidin $S$ and the way it is folded in part of the molecule of insulin. But even if later we find that the connexion in chain configuration is less close than we at present suppose, we think that the atomic arrangement in these peptide molecules is itself of great interest and some importance. Parallel with the work on peptides, we are beginning again to examine the crystal structure of insulin in the light of Dr. Sanger's evidence of its chemical structure.

The present grant from the Rockefeller Foundation ( $£ 3,000$, during a three-year period) is the renewal of a grant made to me over a number of years for research assistance in connexion with these problems. DOROTHY CROWFOOT HODGKIN

\section{Department of Chemical Pathology, St. Mary's Hospital Medical Schoo!, London}

A grant of $£ 4,600$ has been made to the University of London for the purchase of special equipment such as a 'Spinco' preparative ultracentrifuge and an electrophoresis apparatus by the Department of Chemical Pathology at St. Mary's Hospital Medical 